\title{
Environmental variation and the demography and diet of thick-billed murres
}

\author{
Paul A. Smith*, Anthony J. Gaston \\ Environment Canada - National Wildlife Research Centre, Ottawa, Ontario K1A 0H3, Canada
}

\begin{abstract}
Conditions in arctic marine environments are changing rapidly, and understanding the link between environmental and demographic parameters could help to predict the consequences of future change for arctic seabirds. Over 20 yr (1988 to 2007), we studied colony attendance, adult survival and reproductive success of thick-billed murres, as well as the departure masses and diets of their chicks at Coats Island, Nunavut, Canada $\left(62.95^{\circ} \mathrm{N}, 82.00^{\circ} \mathrm{W}\right)$. We evaluated how each parameter responded to climatic conditions near the colony during the breeding season, and in the winter range during the non-breeding period (delineated using geolocation). We used the Arctic Oscillation (AO) and North Atlantic Oscillation indices, as well as local variables to describe ice, oceanographic and weather conditions. We demonstrate that adult survival varied little among years but was higher after winters with lower AO indices, more ice in the south-western part of the winter range in spring, and cooler sea surface temperatures (SST). By comparison, interannual variation in breeding parameters (breeding success, chick mass and diet) was pronounced and responded to SST and ice conditions near the colony. Counts of birds attending the colony, influenced heavily by pre-breeders, were most strongly related to the conditions that influenced adult survival; counts were positively related to ice concentration in the southwest of the winter range. Relationships between climatic conditions and demographic parameters were often lagged, suggesting effects mediated through the food web. The trend towards higher SST and less ice in the vicinity of the colony has not yet reduced reproductive success. However, a significant, ongoing decline in the rate of energy delivery to nestlings suggests that a critical threshold may eventually be crossed.
\end{abstract}

KEY WORDS: Demography $\cdot$ Survival $\cdot$ Reproduction $\cdot$ Climate $\cdot$ Thick-billed murre $\cdot$ Uria lomvia

\section{INTRODUCTION}

Climate variation can affect wildlife populations profoundly, and as concern grows over anthropogenic climate change the urgency of predicting these impacts increases. Past effects of the changing global climate on wildlife are already evident (Hughes 2000, Parmesan \& Yohe 2003), and may be more pronounced at high latitudes (Post et al. 2009, Wassmann et al. 2011). However, prediction of future effects requires an understanding of the link between population processes and environmental variables.
For seabirds, understanding the effects of changing climate is complicated by the fact that they range widely across inaccessible oceanic habitats for much of the year. Changes observed in their breeding behaviour, diet and demography are linked to conditions in the marine environment, and can signal environmental change at a variety of spatial and temporal scales (Cairns 1992, Montevecchi \& Myers 1997). While the link between prey availability and reproduction is probably direct, the effects of environmental variation on demographic processes such as adult survival may be more subtle and may operate outside of the breeding season and away from the colony. 
Many polar seabirds spend 6 mo or more away from their colonies, and because day length and food availability tend to be lowest in winter, we may expect survival to be influenced primarily by conditions in the wintering range (Gaston 2003, Frederiksen et al. 2008). However, until recently, the wintering ranges of many marine birds were poorly documented. With the advent of solar geolocation, knowledge of seabird winter range has expanded rapidly and dramatically (e.g. Phillips et al. 2004, Egevang et al. 2010). The consequent new knowledge of ranges allows us to examine the relationships between environmental conditions and demographic parameters in ways that were not possible previously.

Non-breeding ranges may be hemispheric in scale and habitat use can vary widely among individuals. As population dynamics for marine birds can be influenced by environmental conditions across large portions of the globe and throughout the year, identifying key environmental parameters poses a challenge. Teleconnection indices, such as the North Atlantic Oscillation (NAO) index, are a major source of interannual variability in atmospheric circulation and have been shown to be important predictors of demographic parameters. The NAO, the pressure differential between Iceland and the Azores, can have profound effects on conditions in the marine environment, altering circulation patterns, precipitation regimes, nutrient transport and upwelling (e.g. Déry \& Wood 2004, 2005, Kuzyk et al. 2010). Its influence on food webs is also well documented, including effects on phytoplankton (Edwards et al. 2001), zooplankton (Planque \& Taylor 1998) and fish (Arnott \& Ruxton 2002). Due to the far-reaching effects, NAO values have been correlated with survival and breeding parameters for a variety of seabirds in the North Atlantic (e.g. Grosbois \& Thompson 2005, Sandvik et al. 2008).

The Arctic Oscillation (AO) index describes pressure differences between the polar region and midlatitudes. It is generally highly correlated with the NAO index and the potential effects are analogous to those of the NAO (Stenseth et al. 2003). However, it may capture more of the variation related to recent climatic change in Arctic regions (Aanes et al. 2002). The link between indices based on barometric pressure and the survival of seabirds is necessarily indirect (Forchhammer \& Post 2004), so identifying mechanistic links requires careful model selection and interpretation.

Here, we use 20 yr of observations of thick-billed murres Uria lomvia in the eastern Canadian Arctic and ask how survival and breeding are influenced by conditions in different portions of the range. Wintering areas for this population have been recently described (Gaston et al. 2011). We predicted that conditions at the wintering grounds would have the greatest influence on adult survival and numbers of birds attending the colony, while conditions near the colony would have the greatest influence on parameters related to breeding success and the condition and diet of nestlings. We further predicted that lag effects would be important in models explaining chick diet and growth (where climate effects are mediated through food webs) but less important in models explaining survival, which we predicted to be influenced by contemporary weather or stochastic events. As the climate is changing, particularly in northern regions, we used methods that account for temporal trends in climatic variables. Building on the findings of past studies, we evaluated both largescale climate indices (NAO and AO indices) and environmental variables with finer spatial or temporal resolution (sea surface temperature [SST], ice conditions and extreme weather) to investigate the environmental drivers of demography for this seabird population.

\section{MATERIALS AND METHODS}

\section{Study area and species}

Thick-billed murres Uria lomvia nest on sea cliffs across the circumpolar Arctic and Subarctic. They dive to depths of up to $150 \mathrm{~m}$ to forage on small fish, squid and large zooplankton. Nestlings are fed by both parents for 15 to $30 \mathrm{~d}$ before departing from the breeding site with the male parent (Gaston \& Hipfner 2000).

Field observations were made at a breeding colony of approximately 30000 pairs at Coats Island, Nunavut, Canada $\left(62.95^{\circ} \mathrm{N} 82.00^{\circ} \mathrm{W}\right.$; Gaston et al. 1994), where egg laying begins in mid- to late June and most chicks have left the colony by mid-August. Waters surrounding the colony are classified as low Arctic, and form a part of the Hudson Complex ecoregion which includes Hudson Bay to the south and Foxe Basin to the north (Powles et al. 2004).

\section{Non-breeding range}

Timing of colony departure, routes of migration and wintering locations were determined as part of another study using solar geolocation (Gaston et al. 2011). Locations were available for a sample of 7 


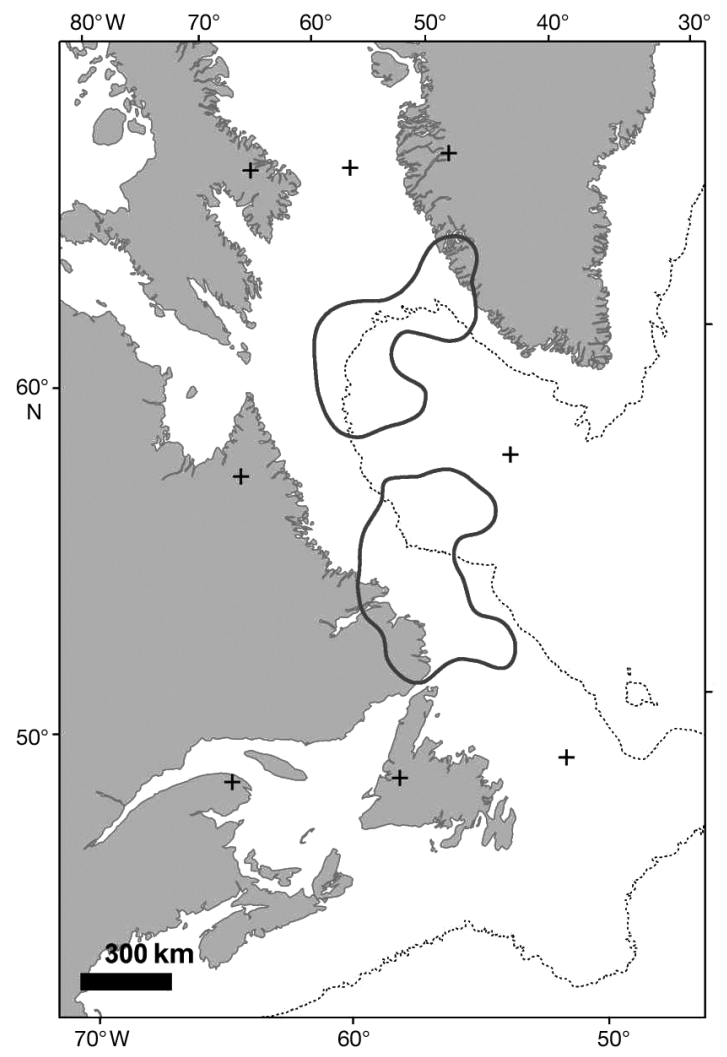

Fig. 1. Uria lomvia. The 8 crosses denote the boundaries within which we evaluated ice conditions and sea surface temperatures; this area encloses the winter range of 17 thick-billed murres followed with light-level geolocators by Gaston et al. (2011). The area was further divided into 4 equal quadrants (centre lines denoted by crosses). Dashed line denotes the $2500 \mathrm{~m}$ depth contour; solid line encircle 2 foci of murres distribution in April $(50 \%$ kernel volume contours)

female and 10 male breeders, from August 2007 until July 2008. All birds remained in Hudson Bay until at least mid-November, after which they moved rapidly through Hudson Strait to winter primarily in the southern Davis Strait and northern Labrador Sea. Most birds remained north of $55^{\circ} \mathrm{N}$, many in areas of heavy ice cover. To summarise the ocean conditions experienced by birds in winter, we defined the wintering area as bounded by $49.0^{\circ}$ to $67.0^{\circ} \mathrm{N}$ and $50.0^{\circ}$ to $65.0^{\circ} \mathrm{W}$ (Fig. 1). This area, measuring 1.8 million $\mathrm{km}^{2}$, encloses the core of the winter area, defined using $50 \%$ kernel volume contours of the complete set of locations, for January to April, for all individuals.

\section{Band resighting}

Chicks and breeding-age adults have been banded at the colony with uniquely coded, field-readable, metal bands since 1985. Adults were captured with noose poles and nestlings were captured by hand at breeding sites during July and August of each year. The band-resighting data used here for estimates of survival are from an intensively monitored portion of the colony (Q-plot), where daily efforts to read bands were carried out during July and August 1990 to 2006. Breeding sites in this area of the colony are very visible, and the sites analysed were selected as the most visible sites. Consequently, the bands of most birds attending this portion of the colony were successfully read each year.

\section{Breeding success}

For this same portion of the colony, we made daily observations to determine the breeding status of individuals, during 1990 to 2007. For each active site, we determined the date of hatch and monitored chicks throughout the nestling period. Chicks that disappeared after 14 or more days of brooding were considered to have departed successfully. Any losses of chicks or eggs that resulted from our research activities were excluded from analyses.

\section{Nestling diet}

We determined the diet fed to nestling thickbilled murres by conducting observations from a blind at Q-plot. Complete methods have been described by Elliott et al. (2008). In brief, observations were made between 04:00 and 22:00 h during late July and early August of each year from 1993 to 2007 for the 46 sites most clearly visible from the blind. For each observation we determined the taxa and size of the prey item(s), and converted this to a caloric value using the methods described by Elliott \& Gaston (2008).

We calculated annual means for the energy value per diet item, the mean number of prey deliveries per active site and the total quantity of energy delivered per chick per hour. We also determined the annual contribution of each of 7 diet categories (Arctic cod, capelin, crustaceans, sandlance, sculpins, other benthic fishes, unidentified/ rare prey) to the total energy delivered to chicks. For some analyses, we reduced the number of parameters for chick diet through a principal component (PC) analysis. We retained components with eigenvalues $>1$, and generated PC scores for use in subsequent analyses. 


\section{Chick mass at departure}

We monitored chick growth for a sample of 50 chicks $>50 \mathrm{~m}$ from plot $\mathrm{Q}$ by measuring mass $\pm 1 \mathrm{~g}$ every 2 to 3 d, in 1988 to 2007 (see Hipfner \& Gaston 1999 or Gaston et al. 2005 for additional details). We used mass at the final observation prior to departure to generate an annual mean mass at departure. We excluded data from 1989, 2002, 2004 and 2007, because in those years we left the field site too early to obtain a representative sample of departure masses.

\section{Colony attendance}

Indices of colony attendance are frequently used as a measure of population size for seabirds (e.g. Birkhead \& Nettleship 1980, Gaston 2003). At Coats Island, the numbers present on 10 plots containing 100 to 500 birds each were counted daily between 17:00 and 18:00 h, during 1990 to 2006. Here, we use the mean daily total count for the period from 25 July to 10 August (see Gaston 2002 for additional details). Most breeding sites were occupied continuously by at least 1 member of the pair during those dates (Gaston \& Nettleship 1982).

\section{Climatic covariates}

We obtained annual and winter (December to March) station-based values for NAO from the Climate Analysis Section, NCAR, Boulder, USA (Hurrell
1995). Monthly mean AO values were obtained from the NOAA Climate Prediction Center (www.cpc. ncep.noaa.gov), and used to generate an AO index for the non-breeding period (September to April). Effects of these indices may be mediated through changes at lower trophic levels (e.g. Stenseth et al. 2004), and adult murres provision their chicks mainly with fish up to 3 yr old (Gaston \& Hipfner 2000). Consequently, we considered lag effects of up to $3 \mathrm{yr}$ in these variables (Table 1).

Ice cover and SST data for the wintering area were obtained from the Hadley Centre of the UK Meteorological Office (badc.nerc.ac.uk/data/hadisst/). Monthly mean values were obtained for the period 1990 to 2006 for the area between $49^{\circ}$ and $67^{\circ} \mathrm{N}$ and $50^{\circ}$ and $65^{\circ} \mathrm{W}$. Grid cells over land were excluded, and a mean value for each month generated. These values were used to generate mean measures of ice concentration and SST for January to March and for April, a time when birds disperse widely (Gaston et al. 2011). Mean ice concentrations in winter and spring vary widely across the winter range of the murres, with generally heavy ice in the west, from Davis Strait down the Labrador Coast, and lighter ice conditions in the east, from Greenland south to offshore waters of the Atlantic (Fig. 1). To detect whether year-to-year variation in different regions affects murre demography differently, we divided the area into 4 equal quadrants and evaluated the influence of ice conditions in these quadrants separately (Table 1, Fig. 1).

Weather data for the wintering range were obtained from a coastal station at Nain, Labrador $\left(56.55^{\circ} \mathrm{N}, 61.68^{\circ} \mathrm{W}\right)$. Monthly values for mean mini-

Table 1. Variables considered in the models. Winter ice conditions were considered for the winter range as a whole, and divided into 4 quadrants. Some variables were considered with time lags of 0 to $3 \mathrm{yr}$ to acknowledge effects that may operate through food webs. AO: Arctic Oscillation index; NAO: North Atlantic Oscillation index; SST: sea surface temperature

\begin{tabular}{|llcl|}
\hline \multirow{2}{*}{ Region of focus } & Variable & Lag effects & Prediction / justification \\
\hline All & AO non-breeding & Yes & Indicates severity of storms, possible food web effects \\
& NAO annual & Yes & Possible links to marine productivity, food web effects \\
& NAO winter & Yes & Possible links to marine productivity, food web effects \\
Winter range divided & Ice, Jan-Mar & No & Affects access to prey \\
into 4 quadrants & Ice, Apr & No & Affects access to prey \\
Winter range & SST, Jan-Mar & Yes & Affects productivity and abundance of prey \\
& SST, Apr & Yes & Affects productivity and abundance of prey \\
& Minimum temperature, Jan-Mar & No & Extreme winter weather may compromise survival \\
& Precipitation, Jan-Mar & No & Extreme winter weather may compromise survival \\
Breeding range & Summer ice concentration, Hudson Bay region & Yes & Affects abundance and availability of prey \\
& SST around breeding colony, annual & Yes & Affects abundance and availability of prey \\
& SST around breeding colony, May-Aug & Yes & Affects abundance and availability of prey \\
& Maximum temperature, May-Aug & No & Potential for heat stress \\
& Maximum wind speed, May-Aug & No & Potential effects on egg loss \\
\hline
\end{tabular}


mum temperatures and mean monthly precipitation were obtained from the National Climate Data and Information Archive of the Weather Office of Environment Canada (www.climate.weatheroffice.gc.ca) for January to March of 1988 to 2007.

We also considered environmental conditions within the breeding range. Annual estimates of ice concentration in the Hudson Bay region on July 16th were obtained from the Canadian Ice Service (iceglaces.ec.gc.ca). We also obtained estimates of the mean annual SST and breeding season (May to August) SST for a $2 \times 2^{\circ}$ block (approximately $220 \times$ $100 \mathrm{~km}$ ) centred on the colony (NOAA ERSST.v3 from www.esrl.noaa.gov/psd/; Smith et al. 2008).

We obtained monthly maximum temperatures and windspeeds from the weather office of Environment Canada for the Coral Harbour weather station (130 km from the breeding colony; www.climate. weatheroffice.gc.ca), and used these to generate means for the breeding season, May to August. As these weather parameters were predicted to affect murres directly, no lag effects were considered.

\section{Analytic methods}

To evaluate support for our predictions, we contrasted the effect of environmental variables from throughout the breeding and non-breeding range. Although care was taken to limit the number of variables considered, the candidate set of models was large in some cases. We employed a detrending technique (see below) to limit spurious correlations, but suggest that the model selection approach be considered exploratory in nature; an attempt to identify patterns for evaluation in future, targeted studies.

We used capture-mark-recapture models, implemented in Program MARK (White \& Burnham 1999), to estimate apparent survival $(\varphi)$ and recapture probability (p). Support was gauged with corrected Akaike's Information Criterion $\left(\mathrm{AIC}_{\mathrm{C}}\right)$, adjusted for small sample sizes and overdispersion $\left(\mathrm{qAIC}_{\mathrm{C} i}\right.$ Burnham \& Anderson 1998). Logit link functions were used for all models. We report parameter estimates $(\beta)$ and $95 \%$ confidence intervals in the logit scale, but also present back-transformed predictions from top models.

The total variance in estimates of survival or resighting probability includes both biological process variance and sampling variance, and accounting for sampling variance can provide more meaningful estimates of among-year patterns (Burnham \& White 2002). We used random effects models to decompose the total variance into process and sampling vari- ance, and shrink year-specific estimates towards the global mean on the basis of sample size (Franklin et al. 2002). We used these 'shrunk' estimates of annual survival and resighting probability to describe the among-year patterns and assess the predictions of our models.

Models to describe interannual variation in colony attendance, breeding success, chick mass at departure and chick diet were constructed using multiple regression in place of mark-recapture methods. Models were ranked with $\mathrm{AIC}_{\mathrm{C}}$ (i.e. no correction for overdispersion), and constant and linear trends were investigated as the reference models.

For each demographic, nestling condition and nestling diet parameter, we contrasted the relative support for models including environmental variables from the breeding and non-breeding range. Variables were grouped into those that influence abundance or availability of prey (e.g. ice, SST), those that summarise extreme weather events (e.g. minimum and maximum temperatures), and large scale teleconnection indices (NAO or $\mathrm{AO}$; see Table 1). We first assessed support for the large scale climate indices (NAO or AO), and then determined whether specific climate variables from either group (i.e. prey, extreme weather), in either the breeding grounds or non-breeding grounds, received support individually or in combination with NAO or AO. With the region and mechanism identified, we built models hierarchically to identify the variables (including lag effects) that most parsimoniously explained demographic parameters. Models including environmental covariates were tested against both a null model and a model with a linear temporal trend. Models containing additional covariates were retained only if they improved model fit by $>2 \mathrm{qAIC}_{\mathrm{C}} / \mathrm{AIC}_{\mathrm{C}}$ units.

Preliminary analyses demonstrated significant trends in some of the predicted variables over time. Several environmental variables also showed significant linear changes over time, and the potential for spurious correlations was therefore high (Graham 2003). As the long-term changes in our demographic (i.e. predicted) variables could result from decadal trends in environmental conditions, we considered models with raw predicted variables and environmental covariates. However, because our primary interest was a more mechanistic understanding of year-to-year fluctuations, we also considered relationships between 'detrended' variables (Grosbois et al. 2008) when temporal trends were apparent in our predicted variables.

We used the Residual Regression method described by Graham (2003), which evaluates the ability of 
environmental variables to explain the residual variation about the underlying temporal trend. Decadal trends in environmental variables were removed by regressing them on year and calculating residuals which were then used in place of the raw environmental covariates in our models. A year effect was included in all models to account for time trends in the predicted variables, and our measures of model support therefore assessed the degree to which environmental variables explained variation about the underlying long-term trends. Model selection following the procedure outlined above was then carried out using detrended environmental variables.

\section{RESULTS}

\section{Variation and covariation in environmental variables}

Winter and spring SSTs in all 4 quadrants of the non-breeding range increased over the period of our study (all R > 0.55). For January to March 1990 to 2007, the increase was estimated to be $0.93^{\circ} \mathrm{C}$ over the entire area (Fig. 2C). Similarly, annual and sum- mer SSTs in the vicinity of the breeding colony increased (all $\mathrm{R}>0.60$; Fig. 2D). Most measures of winter and summer ice cover in the breeding and non-breeding areas decreased during the study period (average $\mathrm{R}=-0.50$; Fig. $2 \mathrm{~A}, \mathrm{~B}$ ), with summer ice near the breeding colony decreasing by an estimated $21 \%$ (Fig. 2B). The winter NAO index also decreased over the study period $(\mathrm{R}=-0.53)$. These observations are consistent with the numerous other accounts of warming and reduced ice concentration in the North Atlantic and eastern Canadian Arctic (e.g. Arctic Climate Impact Assessment 2005). In contrast, our measures of air temperature and wind speed during the breeding season and air temperature and precipitation during the non-breeding season showed no significant patterns.

\section{Adult survival rates}

We included 186 individuals in the study of adult survival. As both survival rates and site tenacity were typically high, the number of newly-marked individuals within the plot was small in some years. This led
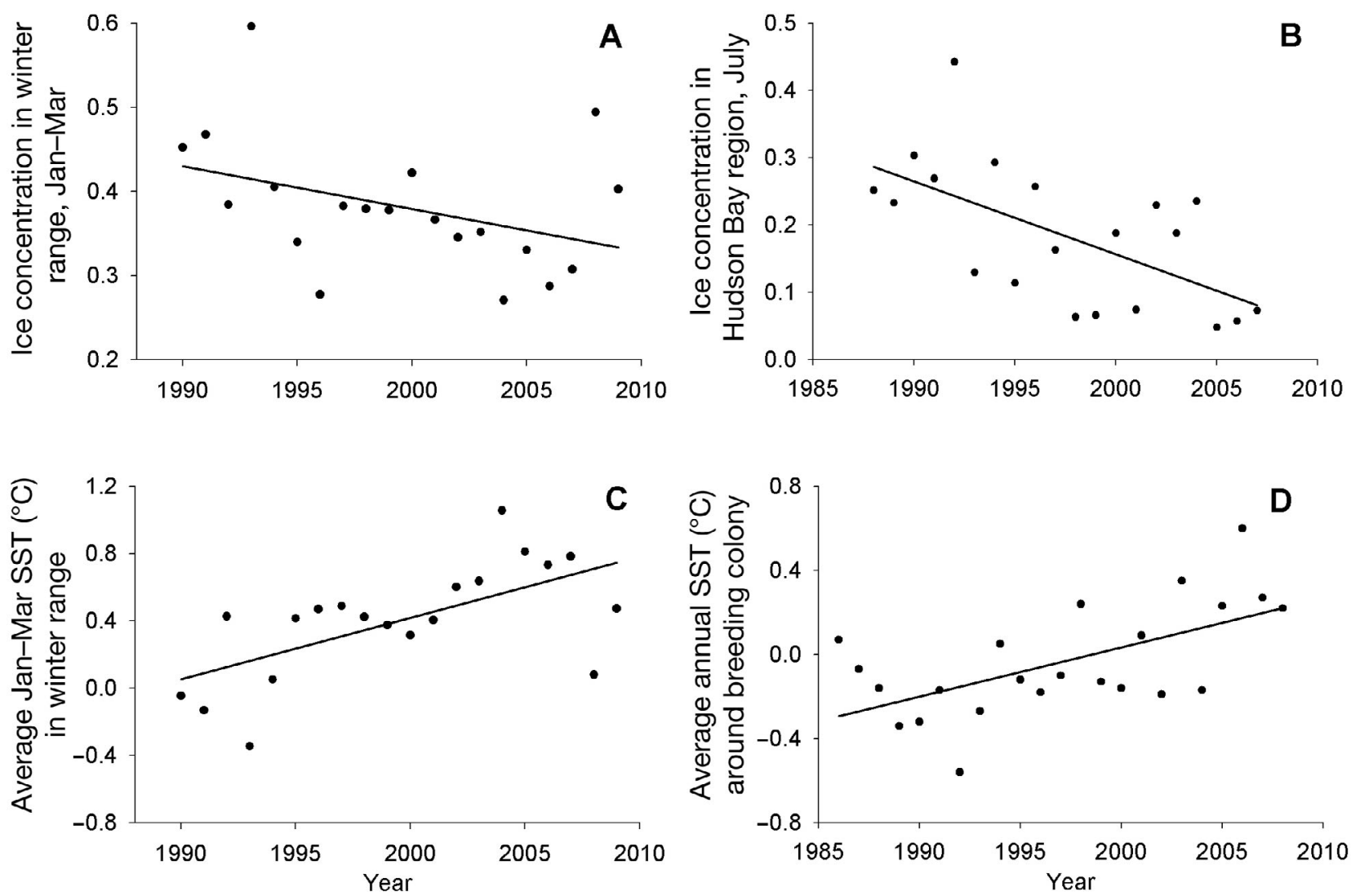

Fig. 2. $(A, B)$ Ice concentration $(1=$ complete coverage) and $(C, D)$ sea surface temperatures $(S S T)$ in $(A, C)$ the winter range and $(\mathrm{B}, \mathrm{D})$ the breeding range of the thick-billed murre Uria lomvia. Solid lines: best fit 
to small expected values in tests of goodness of fit in later years of the study, and some significant differences in the tests of homogeneity of survival ('Test 3' of Program RELEASE; Burnham et al. 1987). Also, some significant lack of fit was identified in Test 2, suggesting the possibility of temporary emigration. Despite this slight lack of fit for the fully timedependent Cormack-Jolly-Seber model, the estimated dispersion parameter, $\hat{c}$, was 1.20 , indicating limited extra-binomial variation overall.

Estimates of apparent adult survival did not vary dramatically among years, yielding a mean $( \pm \mathrm{SD})$ of $0.90 \pm 0.033$ for year-specific estimates. We found little support for year effects in our model selection procedure. Among our structural reference models, those with constant estimates of survival across years received better support than those with year-specific estimates (Table S1 in the supplement at www.int-res. com/articles/suppl/m454p237_supp.pdf). We found no support for linear or quadratic trends in apparent survival. In contrast, we found strong support for quadratic temporal trends in resighting probability (yearspecific estimates varied from 0.86 to 1.00 ; presumably owing in part to our reduced resighting effort in several years in the middle of the study period), and used this quadratic resighting effect when evaluating all subsequent models relating apparent survival to environmental covariates.

Our model selection procedure indicated modest support for an effect of the AO during the nonbreeding season on apparent adult survival. Addition of this climate index reduced the $\mathrm{qAIC}_{\mathrm{C}}$ by 3.0 units

Table 2. Uria lomvia. Environmental variables included in the top model explaining variation in each demographic or diet variable, and the model's Akaike weight $\left(w_{i}\right)$. Additional model selection results appear in Tables S1 to S8 of the supplement. AO: Arctic Oscillation index; NAO: North Atlantic Oscillation index; SST: sea surface temperature. SW: south-west quadrant of wintering range

\begin{tabular}{|llc|}
\hline Predicted variable & Environmental variables in top model & $w_{i}$ \\
\hline Survival, $\varphi$ & AO + Ice April SW & 0.43 \\
Proportion of laid eggs & SST around colony 1 yr lag + NAO 2 yr & 0.57 \\
fledging & lag + Summer SST around colony 2 yr lag & \\
Chick departure mass (g) & SST around colony 1 yr lag & 0.68 \\
Diet PC 1 & Detrended SST around colony 2 yr lag & 0.86 \\
Diet PC 2 & Detrended summer ice Hudson Bay 2 yr & 0.64 \\
& lag + Detrended summer ice Hudson Bay & \\
& 3 yr lag + Detrended Coats summer SST & \\
Energy delivered & 1 yr lag + NAO 2 yr lag & \\
chick ${ }^{-1} \mathrm{~h}^{-1}$ & Detrended SST around colony 2 yr lag + & 0.69 \\
Colony attendance & NAO 3 yr lag & \\
\hline
\end{tabular}

compared to the model with constant survival. Inclusion of additional climate variables improved model fit slightly; a model combining additive effects of AO and winter SST received marginally better support (qAIC ${ }_{C} 2.4$ units lower), as did a model with $\mathrm{AO}$ and ice conditions in April in the south-west quadrant of the wintering range $\left(\mathrm{qAIC}_{\mathrm{C}} 2.5\right.$ units lower than the AO-only model; Table 2, Table S2).

Parameter estimates for the 3 top models all indicated a negative effect of AO (top model: $\beta=-0.69$, $95 \% \mathrm{CI}=-1.20$ to -0.18 , on a logit scale). The variable describing April ice extent in the south-western quadrant of the wintering range had a positive relationship with apparent survival $(\beta=3.65,95 \% \mathrm{CI}=$ 0.24 to 7.06 , on a logit scale), while SST bore a negative relationship with survival $(\beta=-0.91,95 \% \mathrm{CI}=$ -1.78 to -0.04 , on a logit scale). Thus, survival was slightly higher following winters with lower $\mathrm{AO}$ indices, more ice in the southern extent of the winter range, and relatively cooler SSTs.

Support for these parameters was modest, and even the best model was only 5.5 qAIC $_{C}$ units better supported than a model with a constant estimate of survival. Survival as predicted by this top model did not display a tight correspondence with the shrunk year-specific estimates from a random effects model.

\section{Breeding success}

As murres have high breeding-site fidelity, the proportion of chicks departing successfully from a given set of breeding sites might be influenced by whether the adults that bred there previously survived and returned to breed. Accordingly, survival was a significant predictor of departure success $\left(\mathrm{R}^{2}=0.30, \mathrm{p}=0.029\right)$. As the factors influencing survival were explored separately, we used the proportion of eggs that resulted in chicks surviving to departure as our metric of breeding success.

This metric ranged from $54 \%$ to $89 \%$ (mean $\pm \mathrm{SD}=0.69 \pm 0.088$ ). No significant increases or decreases over time were identified. The most influential single predictor of breeding success was the SST in the vicinity of the colony, lagged by 1 yr. This model was a marginal improvement over a null model $\left(\mathrm{AIC}_{\mathrm{C}} 2.1\right.$ units lower; Table S3), but received more substan- 
tial support when an effect of NAO (2 yr lag) was included. The top model $\left(\mathrm{R}^{2}=0.61\right.$; an improvement of $6.9 \mathrm{AIC}_{\mathrm{C}}$ units over the null model) also included an effect of summer SST near the colony, lagged by 2 yr (Table 2). Parameter estimates were all positive $\left(\beta_{\mathrm{SST} \text { colony } 1 \mathrm{yr} \text { lag }}=17.9 \pm 5.4, \beta_{\mathrm{NAO} 2 \mathrm{yr} \text { lag }}=3.0 \pm 0.8\right.$, $\beta_{\text {Summer SST colony } 2 \text { yr lag }}=10.6 \pm 4.6$ ), suggesting that breeding success was higher when SSTs and the NAO index in previous years were higher.

\section{Departure mass}

The mean mass of departing chicks varied among years from $212 \pm 27 \mathrm{~g}$ to $245 \pm 23 \mathrm{~g}$. SST in the vicinity of the colony lagged by 1 yr was found to be the most influential single predictor of chick mass at departure. Years with higher past SSTs were associated with lower departure masses $\left(\beta=-33.3 \pm 12.17, R^{2}=\right.$ 0.33; Table S4). No additional covariates improved model fit. This top model was only an improvement of $3.4 \mathrm{AIC}_{\mathrm{C}}$ units over the null model, however, and only 2.5 units better supported than a linear trend in departure mass. This latter effect, a linear decline in departure mass, was not significant at $\alpha=0.05$, and no detrended analyses were therefore explored (mass vs. year $\mathrm{R}^{2}=0.22, \mathrm{p}=0.06$ ).

\section{Chick diet}

When chick diet was condensed into orthogonal PCs, PC1 and PC2 captured $76 \%$ of the variability in diet. PC1 loadings were large and negative for cod and large and positive for crustaceans, sculpins and other benthic fishes (Table 3). A low PC1 score therefore reflected a diet rich in cod. PC1 for chick diet was correlated with both the total energy delivered per chick per hour (linear regression PC1 vs. kJ chick $^{-1}$

Table 3. Uria lomvia. Component loadings for the first 2 principal components (PC1 and PC2) of chick diet, explaining 45 and $31 \%$ of variability in annual diet, respectively. Diet was described as the proportion of energy contributed from each of the diet item categories listed below

\begin{tabular}{|lrr|}
\hline Diet item & PC1 & PC2 \\
\hline Arctic cod & -0.84 & -0.51 \\
Capelin & 0.52 & 0.82 \\
Crustaceans & 0.85 & -0.09 \\
Other benthic fishes & 0.88 & -0.22 \\
Sandlance & -0.17 & 0.90 \\
Sculpins & 0.68 & -0.33 \\
Unidentified/rare prey & 0.44 & -0.47 \\
\hline
\end{tabular}

$\left.\mathrm{h}^{-1}, \mathrm{R}^{2}=0.35, \mathrm{p}=0.02\right)$ and the average energy content per feed $\left(\mathrm{R}^{2}=0.45, \mathrm{p}=0.006\right)$. Low PC1 scores (i.e. a diet high in cod) were associated with high levels of total energy delivered to chicks and also the delivery of individual prey items with high energy contents. PC1 was a highly significant predictor of departure mass, with a low PC1 score related to a high departure mass $\left(\mathrm{R}^{2}=0.57, \mathrm{p}=0.005\right)$. PC1 was unrelated to breeding success.

The second diet component, PC2, loaded negatively on cod and positively on capelin and sandlance. In contrast to PC1, PC2 was most closely related to the number of feeds per chick per hour, with a low PC2 score (i.e. a diet high in sandlance and capelin) associated with a high rate of feeding $\left(\mathrm{R}^{2}=0.33, \mathrm{p}=0.03\right)$. Although not significant individually, this diet variable did add significantly to the prediction of departure mass among years; after accounting for the effect of PC1, a high PC2 score was associated with higher departure mass (departure mass vs. PC1 + PC2: $\beta_{\mathrm{PC} 1}=-9.13 \pm 2.19, \beta_{\mathrm{PC} 2}=$ $\left.5.68 \pm 2.47, R^{2}=0.73, p=0.003\right)$. PC2 was therefore a weaker predictor of departure mass, but in contrast to PC1, a high PC2 was associated with higher breeding success $\left(\beta_{\mathrm{PC} 2}=5.13 \pm 2.16, \mathrm{R}^{2}=0.30, \mathrm{p}=0.03\right)$.

Temporal trends in PC1 were significant (PC1 vs. year, $R^{2}=0.31, \mathrm{p}=0.03$ ), as a result of a pronounced decline in the proportion of cod in the diet. The top model to explain PC1 including raw environmental covariates suggests an influence of SST in the vicinity of the colony and NAO lagged by $1 \mathrm{yr}\left(\mathrm{R}^{2}=0.59\right)$. Higher SSTs $(\beta=2.19 \pm 0.75$; Table S5) and lower NAO values $(\beta=-0.20 \pm 0.09)$ are associated with higher PC1 scores (less cod, more benthic fishes and crustaceans). However, these results may reflect the strong general increase in SST and strong general decrease in proportion of cod in the diet. With these temporal trends accounted for, the SST around the colony (2 yr lag) was found to be the strongest predictor of PC1 score $\left(\mathrm{R}^{2}=0.57\right)$, but here, lower past SSTs are associated with a higher PC1 score $(\beta=$ $-2.65 \pm 0.98)$. As a high PC1 score reflects an energypoor diet, this result is consistent with the abovedescribed finding that energy content delivered to chicks was lower when past SSTs were lower.

Temporal trends in PC2 were also significant $\left(\mathrm{R}^{2}=\right.$ $0.32, \mathrm{p}=0.03)$; PC2 scores declined during the study period, reflecting an increase in the proportion of capelin and sandlance at the expense of cod. Among raw environmental variables, the strongest predictors of PC2 were lagged summer ice concentrations in the Hudson Bay region (2 and $3 \mathrm{yr}$ lags, $\mathrm{R}^{2}=0.68$; Table S6). Support for the ice variables was strong; 
the model with both ice variables was an improvement of more than $10 \mathrm{AIC}_{\mathrm{C}}$ units over the null model. The model building procedure with detrended variables showed similar results, with greatest support for summer ice concentrations in the Hudson Bay region (2 and 3 yr lags), and additional support for NAO (2 yr lag) and past summer SST (1 yr lag) in the vicinity of the colony $\left(\mathrm{R}^{2}\right.$ for top model $\left.=0.90\right)$. For both model building procedures, the ice parameters were negative, suggesting that low past ice concentrations were associated with high PC2 scores (high proportion of capelin and sandlance in the diet). Parameter estimates for SST and NAO suggested that lower past SST and higher past values for the NAO index were associated with higher PC2 scores for nestling diet.

The rate of energy delivered to chicks varied more than 2-fold among years, and although variable, this quantity declined significantly over the period of our study, from a predicted $15.3 \mathrm{~kJ}$ chick $^{-1} \mathrm{~h}^{-1}$ in 1990 to $9.5 \mathrm{~kJ} \mathrm{chick}^{-1} \mathrm{~h}^{-1}$ in 2007 (energy vs. year, $\mathrm{R}^{2}=0.28$, $\mathrm{p}=0.04)$. This decline reflected a decrease in the average energy content of feeds, rather than a decrease in the number of feeds (linear regression of energy per feed vs. year, $R^{2}=0.56, p=0.001, \beta_{\text {Year }}=-1.85 \pm 0.43$; number of feeds vs. year, $\mathrm{R}^{2}=0.11, \mathrm{p}=0.22$ ).

The strongest single predictor of the quantity of energy delivered to chicks (for raw variables) was NAO with a lag of $3 \mathrm{yr}$ (Table S7), with higher NAO values corresponding with greater quantities of energy delivered to chicks $\left(\beta=0.83 \pm 0.288, R^{2}=0.39\right)$. With time trends removed, NAO 3 yr lag remained in the top model, but SST (2 yr lag) had greater support as an individual predictor (Table S7). In the top detrended model $\left(\mathrm{R}^{2}=0.80\right)$, higher past SSTs and higher NAO values were associated with greater quantities of energy delivered $\left(\beta_{\text {Detrended NAO } 3 \mathrm{yr} \text { lag }}=0.50 \pm 0.21\right.$, $\beta_{\text {Detrended SST colony } 2 \text { yr lag }}=8.94 \pm 2.09$; Table 2 ).

\section{Colony counts}

The total number of birds counted in fixed plots varied among years, but increased over time (35 birds $\left.\mathrm{yr}^{-1}, \mathrm{R}^{2}=0.75, \mathrm{p}<0.001\right)$. Inclusion of a linear year effect improved model fit by more than $20 \mathrm{AIC}_{\mathrm{C}}$ units over the null model, and this model received greater support than any model with raw environmental covariates $\left(\mathrm{R}^{2}=0.78\right.$; Table S8). Models including summer SST at the breeding grounds (1 and 0 yr lags) and ice conditions in the south-west of the wintering grounds received greater support than the null model, and achieved lower deviance than a linear time trend, but this improved fit did not justify the additional pa- rameters (Table S8). Parameter estimates for the model including summer SSTs and winter ice conditions suggested higher colony attendance when current and past SSTs near the colony were warmer and when ice conditions in the southern extent of the previous winter were heavier. However, the strong temporal trends evident in both SST and colony counts could lead to spurious correlations.

With the longer-term temporal trends removed, current and past SSTs near the colony were poor predictors of counts, with $\mathrm{AIC}_{\mathrm{C}}$ values at least 2 units greater than the model including only a year effect. The top model for detrended environmental variables included only the effect of April ice in the south-western quadrant of the non-breeding range (Table 2, Table S8). Parameter estimates for this effect were positive, suggesting that colony attendance was higher after a spring with heavy ice conditions $\left(\beta_{\text {Ice April Sw }}=701.9 \pm 326.3, \mathrm{R}^{2}=0.83\right)$. Although this model was only a small improvement, $1.4 \mathrm{AIC}_{\mathrm{C}}$ units, over the year-effect-only model, predictions from this top model fit the observed colony counts well.

\section{DISCUSSION}

We found that variation in environmental conditions could explain a substantial proportion of the variation in the demographic and diet parameters. Although a large number of variables were considered, a small number of key variables were recurrent in top models. Teleconnection indices, such as the $\mathrm{AO}$ and NAO indices, were present in some top models, but local measurements of environmental conditions generally received stronger support. Moreover, survival and counts of birds attending the colony were influenced most by conditions on the wintering grounds, whereas, not surprisingly, breeding success and chick diet were influenced most by conditions encountered near the breeding colony. Importantly, many relationships involved time lags of 1 to 3 yr, suggesting that climatic effects were indirect, mediated through changes in food availability and predator-prey interactions.

\section{Survival}

Despite a long time series, no catastrophic mortality events were identified: the lowest estimate of annual survival was $84 \%$. However, we found that the variation in survival was best predicted by winter conditions, specifically ice concentrations and SSTs 
in the winter range and the $\mathrm{AO}$ during the nonbreeding season. In all cases, the variables were included in models without lag effects, potentially suggesting that they were affecting murres directly, for example by impairing access to prey.

A positive phase of the $\mathrm{AO}$, associated with lower apparent survival in our study, is associated with a more intense polar vortex, with ocean storms driven farther north by relatively higher pressure at midlatitudes (Serreze et al. 1995). The polar vortex also traps cold air at northern latitudes, and areas in the wintering grounds of murres (i.e. between Labrador, Newfoundland and Greenland) are colder than during the negative phase. Colder SSTs in the wintering range were actually associated with higher rates of survival. However, the stormy conditions in the North Atlantic during years with a positive AO index could significantly impair foraging. High winds and waves reduce the success rate of foraging common murres Uria aalge during the breeding season, increasing the amount of time they spend foraging and reducing the mean energetic value of the prey captured (Finney et al. 1999). Reduced foraging efficiency, coupled with the increased costs of thermoregulation during colder, stormier winters, could account for the effects of the $\mathrm{AO}$ on apparent survival that we observed.

We also documented a positive link between spring ice concentration in the south-west of the wintering range and adult survival. The spring ice cover in this area is substantial, with a mean $( \pm \mathrm{SD})$ among years of $69 \pm 8 \%$. The preference of Atlantic thickbilled murres for foraging in and around ice during the breeding season is well documented (e.g. Gaston \& Hipfner 1998), and wintering birds also feed heavily on ice-associated prey such as Arctic cod and hyperiid amphipods (Rowe et al. 2000). Analyses of stomach contents and stable isotopes suggest that ice-associated crustaceans may in fact become a more significant component of the diet in late winter and early spring (Elliot et al. 1990, Moody \& Hobson 2007). The presence of broken ice and ice edges concentrates prey in the upper water column where they are readily accessible to foraging murres (Bradstreet 1980). Birds' access to higher ice concentrations in the winter range in April may facilitate feeding prior to the migration through Hudson Strait in May.

\section{Breeding success, chick mass and diet}

Local SSTs and ice variables with lags of 1 and/or

2 yr were present in the top models for breeding success, departure mass, rate of energy delivery to chicks and both PC1 and PC2 of chick diet. The presence of time lags in these effects, and, in particular, the evidence of lagged effects in the energy delivery and diet variables, suggests that this environmental variation affects murres through changes at lower trophic levels.

During the breeding season, adult thick-billed murres forage heavily on both fish and invertebrates (Gaston \& Bradstreet 1993, Moody \& Hobson 2007, Provencher et al. 2012, this Theme Section). However, murres are single prey loaders, and in comparison to large and energy-rich fish, invertebrates constitute a poor diet item for nestlings. The fish fed to nestlings are typically $>1 \mathrm{yr}$ old (Elliott \& Gaston 2008), suggesting that conditions in past years could influence the strength of the year classes of fish targeted by foraging murres. After accounting for strong temporal trends, our results show that higher SSTs in the vicinity of the colony $2 \mathrm{yr}$ previously were associated with greater quantities of energy delivered to chicks. Similarly, a detrended analysis demonstrated that higher SSTs 2 yr previously were associated with a lower PC1 score; a diet high in energy-rich Arctic cod and low in energy-poor crustaceans and benthic fish. Finally, higher SSTs in the vicinity of the colony in the previous 2 yr also contributed to greater breeding success.

It is important to note that our results suggesting positive effects of SST are from analyses with significant time trends removed. Annual and summer SST in the vicinity of the colony increased significantly over the period of study by an estimated $0.52^{\circ} \mathrm{C}$ and $0.88^{\circ} \mathrm{C}$, respectively. Summer ice cover also declined (Gaston et al. 2005, Tivy et al. 2011, present study). During this time, the rate of energy delivered to chicks declined significantly, and although not significant, a trend towards lower departure masses was also observed. Trends in the diet PCs (and direct observations of nestling diets) suggest a decline in the contribution of cod and an increase in the contribution of capelin, sandlance, crustaceans and benthic fish to nestling diet. Although slightly higher SSTs in year $t-2$ might have been associated with an increase in the proportion of cod in the diet, the large changes over the period of study may have fostered a regime shift towards a more sub-arctic assemblage of forage fishes, dominated by capelin and sandlance (e.g. Gaston 2003).

We also found that phase of the NAO, with time lags of 2 or $3 \mathrm{yr}$, was positively related to breeding success, rates of energy delivery to nestlings, and the proportion of capelin and sandlance in the diet (i.e. 
high PC2). The NAO is associated with several phenomena that could influence the availability of prey near the Coats Island colony: for instance, interannual variation in precipitation, and consequently freshwater discharge into arctic marine environments including Hudson Bay (Déry \& Wood 2004, 2005). Inflow of freshwater into Hudson Bay, in turn, plays a critical role in patterns of circulation, upwelling and the transport of macronutrients that support primary production (Kuzyk et al. 2010). Although the link between higher NAO index in year $t-2$ and breeding success and chick diet at Coats Island requires further investigation, it is clear that the pressure differential described by this teleconnection index could influence the abundance and distribution of the murres' prey.

\section{Colony attendance}

A striking feature of the Coats Island colony in recent decades has been a pronounced increase in counts of attending birds over time. Gaston (2003) reported that year-to-year changes in counts of murres at Coats Island were positively related to body condition, and reached the conclusion that foraging conditions in winter may be driving this index of population size. After detrending, we found that more ice in spring in the south-western extent of the breeding range increased colony counts in the following summer; the same variable that was found to influence adult survival. Our mean rate of adult survival was similar to that observed for thick-billed murres breeding at Hornøya, in the Western Barents Sea (91.6\%, 1989 to 2002; Sandvik et al. 2005), where a trend towards increasing colony attendance is ongoing. However, although year-to-year changes in ice cover are positively related to colony attendance, overall trends in ice cover in the winter range are weakly negative and cannot therefore explain the general trend of increasing counts.

Despite high elasticity, adult survival is often relatively invariant in seabirds and may therefore contribute little to variation in the population growth rate, $\lambda$. For example, despite contrasting population trends ranging from -3 to $+11 \%$ per annum, the annual survival rates of Atlantic puffins Fratercula arctica in 5 colonies spanning the species' range in the east Atlantic were virtually identical over a 10 to $15 \mathrm{yr}$ period (Harris et al. 2005). Although breeding success is often highly variable, $\lambda$ is usually relatively insensitive to variation in reproduction (Sæther \& Bakke 2000). Pre-breeding survival, in contrast, can vary markedly and also have a substantial influence on $\lambda$ (Reid et al. 2004, Robinson et al. 2004). Prebreeding survival was not studied here, but future studies relating pre-breeding survival to environmental conditions could aid in interpretation of trends in this population.

\section{Consequences of future climate change}

In general, our results suggest that breeding for thick-billed murres in northern Hudson Bay improved with a slight year-to-year warming, a result consistent with the findings of Irons et al. (2008). However, in Irons et al.'s analysis of population growth rates from colonies across the circumpolar breeding range of the species, the authors demonstrated that populations responded positively to slight warming but negatively to larger changes. We found that rates of energy delivery to chicks declined over the period of our observations, that chick diet shifted dramatically, and that departure masses of chicks also may have declined. Despite the fact that adults fed their nestlings diet items of lower energetic value, the rate of feeding did not increase, suggesting that adults may have limited capacity to increase delivery rates. Although breeding success has not yet changed, it seems plausible that if energy delivery rates continue to decline, a threshold may be reached beyond which reproductive success will suffer.

\section{LITERATURE CITED}

Aanes R, Sæther BE, Smith FM, Cooper EJ, Wookey PA, Øritsland NA (2002) The Arctic Oscillation predicts effects of climate change in two trophic levels in a higharctic ecosystem. Ecol Lett 5:445-453

Arctic Climate Impact Assessment (ACIA) (2005) Cambridge University Press. www.acia.uaf.edu

> Arnott SA, Ruxton G (2002) Sandeel recruitment in the North Sea: demographic, climatic and trophic effects. Mar Ecol Prog Ser 238:199-210

Birkhead TR, Nettleship DN (1980) Census methods for murres, Uria species: an integrated approach. Canadian Wildlife Service Occasional Paper 43, Ottawa

Bradstreet MSW (1980) Thick-billed murres and black guillemots in the Barrow Strait area, N.W.T., during spring: diets and food availability along ice edges. Can J Zool 58:2120-2140

Burnham KP, Anderson DR (1998) Model selection and inference: a practical information-theoretic approach. Springer-Verlag, New York, NY

$>$ Burnham KP, White GC (2002) Evaluation of some random effects methodology applicable to bird ringing data. J Appl Stat 29:245-264

Burnham KP, Anderson DR, White GC, Brownie C, Pollock $\mathrm{KH}$ (1987) Design and analysis methods for fish survival 
experiments based on release-recapture. Am Fish Soc Monogr 5:1-437

Cairns DK (1992) Bridging the gap between ornithology and fisheries science: use of seabird data in stock assessment models. Condor 94:811-824

Déry SJ, Wood EF (2004) Teleconnection between the Arctic Oscillation and Hudson Bay river discharge. Geophys Res Lett 31:L18205. doi:10.1029/2004GL020729

> Déry SJ, Wood EF (2005) Decreasing river discharge in northern Canada. Geophys Res Lett 32:L10401. doi: 10.1029/2005GL022845

Edwards M, Reid P, Planque B (2001) Long term regional variability of phytoplankton biomass in the northeast Atlantic (1960-1995). ICES J Mar Sci 58:39-49

Egevang C, Stenhouse IJ, Phillips RA, Petersen A, Fox JW, Silk JRD (2010) Tracking of Arctic terns Sterna paradisaea reveals longest animal migration. Proc Natl Acad Sci USA 107:2078-2081

Elliot RD, Ryan PC, Lidster WW (1990) The winter diet of thick-billed murres in coastal Newfoundland waters. Stud Avian Biol 14:125-138

Elliott KH, Gaston AJ (2008) Mass-length relationships and energy content of fishes and invertebrates delivered to nestling thick-billed murres Uria lomvia in the Canadian Arctic, 1981-2007. Mar Ornithol 36:25-33

Elliott KH, Davoren GK, Gaston AJ (2008) Sources of bias in observations of murre provisioning behaviour. J Field Ornithol 79:298-307

Finney SK, Wanless S, Harris MP (1999) The effect of weather conditions on the feeding behaviour of a diving bird, the common guillemot Uria aalge. J Avian Biol 30: 23-30

> Forchhammer MC, Post E (2004) Using large-scale climate indices in climate change ecology studies. Popul Ecol 46: $1-12$

- Franklin AB, Anderson DR, Burnham KP (2002) Estimation of long term trends and variation in avian survival probabilities using random effects models. J Appl Stat 29: 267-287

> Frederiksen M, Daunt F, Harris MP, Wanless S (2008) The demographic impact of extreme events: stochastic weather drives survival and population dynamics in a long-lived seabird. J Anim Ecol 77:1020-1029

Gaston AJ (2002) Results of monitoring thick-billed murre populations in the eastern Canadian Arctic, 1976-2000. Can Wild Ser Occ Pap 106, Ottawa

Gaston AJ (2003) Synchronous fluctuations of thick-billed murre (Uria lomvia) colonies in the Eastern Canadian Arctic suggest population regulation in winter. Auk 120: 362-370

Gaston AJ, Bradstreet MSW (1993) Intercolony differences in the summer diet of thick-billed murres in the eastern Canadian Arctic. Can J Zool 71:1831-1840

Gaston AJ, Hipfner M (1998) The effect of ice conditions in northern Hudson Bay on breeding by thick-billed murres (Uria lomvia). Can J Zool 76:480-492

Gaston AJ, Hipfner JM (2000) Thick-billed murre (Uria lomvia). In: Poole A, Gill F (eds) The birds of North America, No. 497. The Birds of North America, Philadelphia, PA.

Gaston AJ, Nettleship DN (1982) Factors determining seasonal changes in attendance at colonies of the thickbilled murre Uria lomvia. Auk 9:468-473

Gaston AJ, de Forest LN, Donaldson G, Noble DG (1994) Population parameters of thick-billed murres at Coats
Island, Northwest Territories, Canada. Condor 96: 935-948

Gaston AJ, Gilchrist HG, Hipfner JM (2005) Climate change, ice conditions and reproduction in an Arctic nesting marine bird: Brunnich's guillemot (Uria lomvia L.). J Anim Ecol 74:832-841

Gaston AJ, Smith PA, Tranquilla L, Montevecchi WA and others (2011) Movements and wintering areas of breeding age thick-billed murres Uria lomvia from two colonies in Nunavut, Canada, as determined by solar geolocation. Mar Biol 158:1929-1941

Graham MH (2003) Confronting multicollinearity in ecological multiple regression. Ecology 84:2809-2815

> Grosbois V, Thompson PM (2005) North Atlantic climate variation influences survival in adult fulmars. Oikos 109: 273-290

> Grosbois V, Gimenez O, Gaillard JM, Pradel R and others (2008) Assessing the impact of climate variation on survival in vertebrate populations. Biol Rev Camb Philos Soc 83:357-399

Harris MP, Anker-Nilssen T, McCleery RH, Erikstad KE, Shaw DN, Grosbois V (2005) Effect of wintering area and climate on the survival of adult Atlantic puffins Fratercula arctica in the eastern Atlantic. Mar Ecol Prog Ser 297:283-296

Hipfner JM, Gaston AJ (1999) The relationship between egg size and posthatching development in the thick-billed murre. Ecology 80:1289-1297

Hughes L (2000) Biological consequences of global warming: Is the signal already apparent?. Trends Ecol Evol 15:56-61

> Hurrell JW (1995) Decadal trends in the North Atlantic oscillation: regional temperatures and precipitation. Science 269:676-679

> Irons DB, Anker-Nilssen T, Gaston AJ, Byrd GV and others (2008) Magnitude of climate shift determines direction of circumpolar seabird population trends. Glob Change Biol 14:1455-1463

Kuzyk ZZA, Macdonald RW, Tremblay JÉ, Stern GA (2010) Elemental and stable isotopic constraints on river influence and patterns of nitrogen cycling and biological productivity in Hudson Bay. Cont Shelf Res 30:163-176

- Montevecchi WA, Myers RA (1997) Centurial and decadal oceanographic influences on changes in northern gannet populations and diets in the north-west Atlantic: implications for climate change. ICES J Mar Sci 54:608-614

Moody AT, Hobson KA (2007) Alcid winter diet in the northwest Atlantic determined by stable isotope analysis. Mar Ornithol 35:39-46

> Parmesan C, Yohe G (2003) A globally coherent fingerprint of climate change impacts across natural systems. Nature 421:37-42

$>$ Phillips RA, Silk JRD, Croxall JP, Afanasyev V, Briggs DR (2004) Accuracy of geolocation estimates for flying seabirds. Mar Ecol Prog Ser 266:265-272

> Planque B, Taylor AH (1998) Long-term changes in zooplankton and the climate of the north Atlantic. ICES J Mar Sci 55:644-654

Post E, Forchhammer MC, Bret-Harte MS, Callaghan TV and others (2009) Ecological dynamics across the Arctic associated with recent climate change. Science 325: $1355-1358$

Powles H, Vendette V, Siron R, O'Boyle B (2004) Proceedings of the Canadian marine ecosystems workshop. DFO Can Sci Advis Sec Proceed Ser 2004/01 
Provencher JF, Gaston AJ, O'Hara PD, Gilchrist HG (2012) Seabird diet indicates changing Arctic marine communities in eastern Canada. Mar Ecol Prog Ser 454:171-182

Reid JM, Bignal EM, Bignal S, McCracken DI, Monaghan P (2004) Identifying the demographic determinants of population growth rate: a case study of red-billed choughs Pyrrhocorax pyrrhocorax. J Anim Ecol 73:777-788

Robinson RA, Green RE, Baillie SR, Peach WJ, Thomson DL (2004) Demographic mechanisms of the population decline of the song thrush Turdus philomelos in Britain. J Anim Ecol 73:670-682

Rowe S, Jones IL, Chardine JW, Elliot RD, Veitch BG (2000) Recent changes in the winter diet of murres (Uria spp.) in coastal Newfoundland waters. Can J Zool 78:495-500

Sæther BE, Bakke $\varnothing$ (2000) Avian life history variation and contribution of demographic trait to the population growth rate. Ecology 81:642-653

Sandvik H, Erikstad KE, Barrett R, Yoccoz NG (2005) The effect of climate on adult survival in five species of North Atlantic seabirds. J Anim Ecol 74:817-831

Sandvik H, Coulson T, Sæther BE (2008) A latitudinal gradient in climate effects on seabird demography: results from interspecific analyses. Glob Change Biol 14:703-713

Serreze MC, Barry RG, Rehder MC, Walsh JE (1995) Variability in atmospheric circulation and moisture flux over

Submitted: February 18, 2011; Accepted: January 9, 2012 the Arctic. Philos Trans R Soc Lond A 352:215-225

Smith TM, Reynolds RW, Peterson TC, Lawrimore J (2008) Improvements to NOAA's historical merged land-ocean surface temperature analysis (1880-2006). J Clim 21: 2283-2296

Stenseth NC, Ottersen G, Hurrell JW, Mysterud A and others (2003) Studying climate effects on ecology through the use of climate indices: the North Atlantic Oscillation, El Niño Southern Oscillation and beyond. Proc R Soc Lond B 270:2087-2096

Stenseth NC, Ottersen G, Hurrel JW, Belgrano A (2004) Marine ecosystems and climate variation. The North Atlantic: a comparative perspective. Oxford University Press, Oxford

Tivy A, Howell SEL, Alt B, McCourt S and others (2011) Trends and variability in summer sea ice cover in the Canadian Arctic based on the Canadian Ice Service Digital Archive, 1960-2008 and 1968-2008. J Geophys Res C 116:C03007. doi:10.1029/2009JC005855

> Wassmann P, Duarte CM, Agust S, Sejr MK (2011) Footprint of climate change in the Arctic marine ecosystem. Glob Change Biol 17:1235-1249

White GC, Burnham KP (1999) Program MARK: Survival estimation from populations of marked animals. Bird Study 46 (Suppl):120-138

Proofs received from author(s): March 7, 2012 